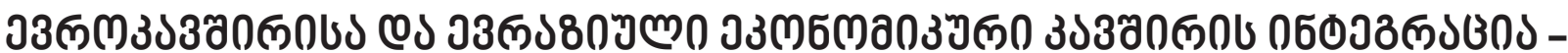

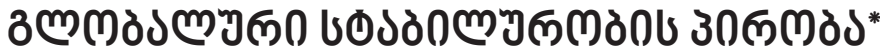

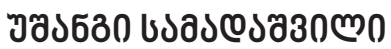

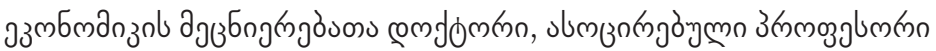

https://doi.org/10.35945/gb.2018.06.029

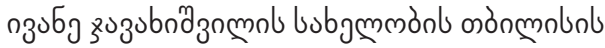

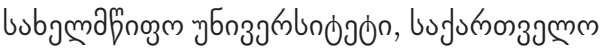

u.samadashvili@mail.ru

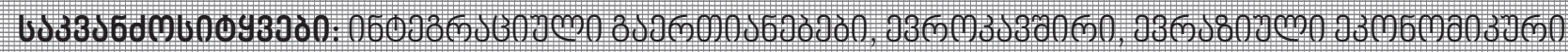

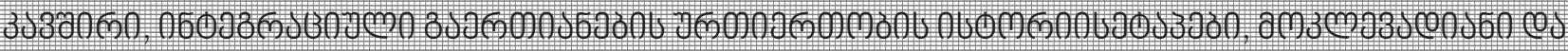
3600003000060103030000

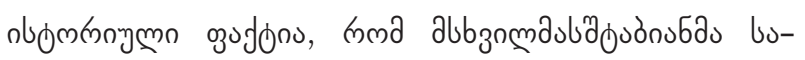

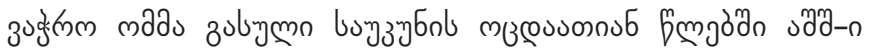

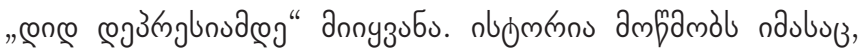

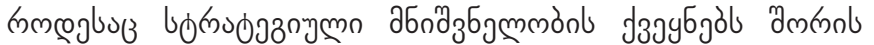

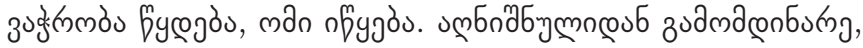

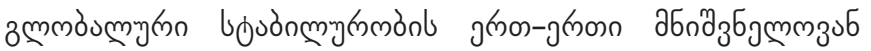

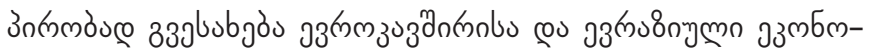

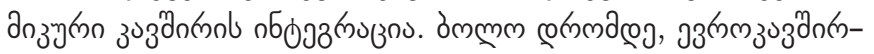

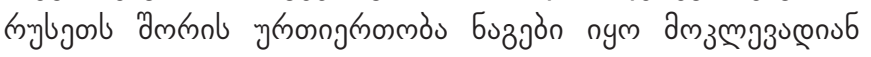

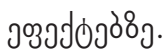

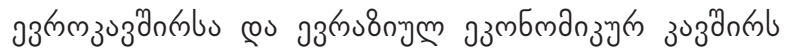

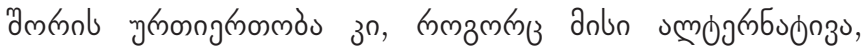

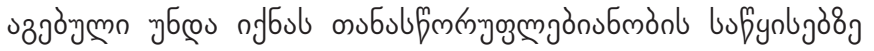

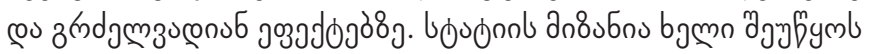

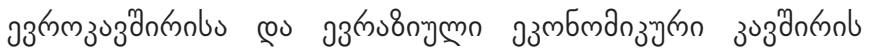

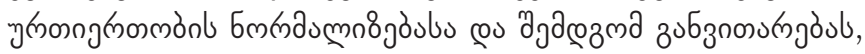

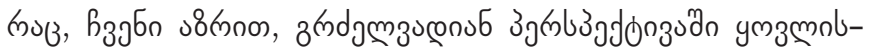

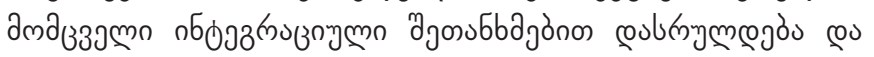

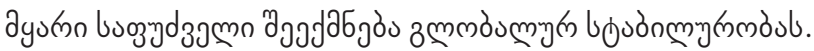

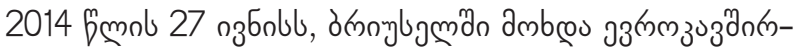

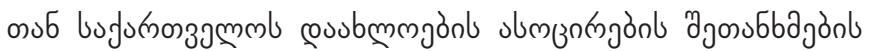

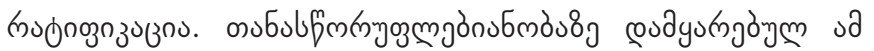

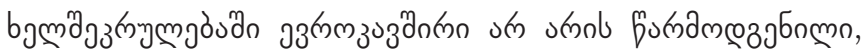

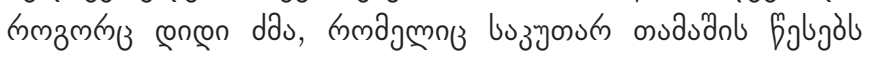

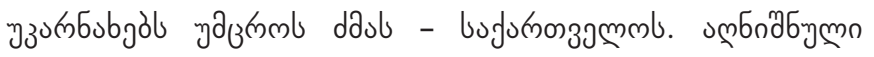

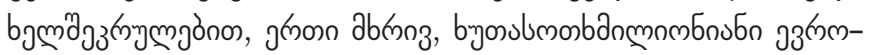

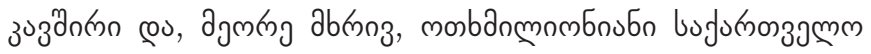

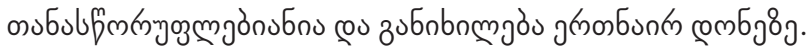

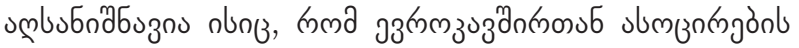

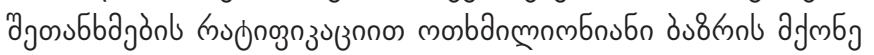

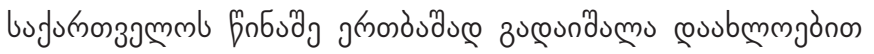

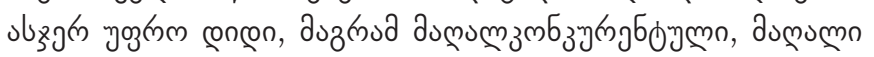

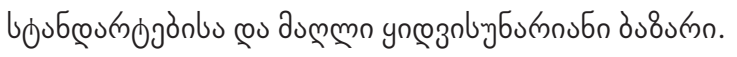

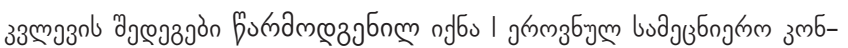
бुgr dngos"

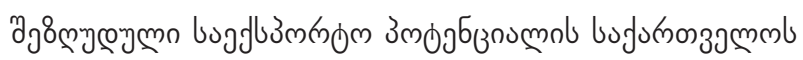

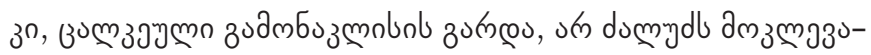

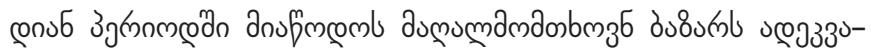

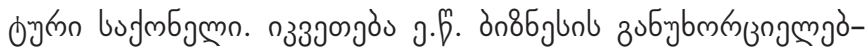

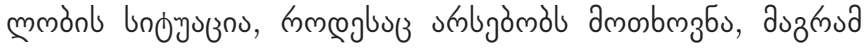

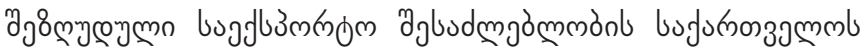

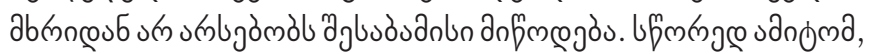

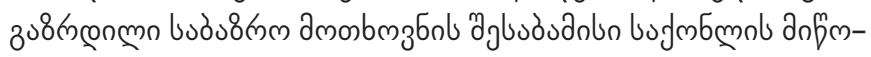

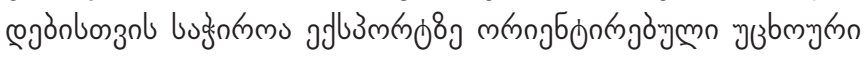

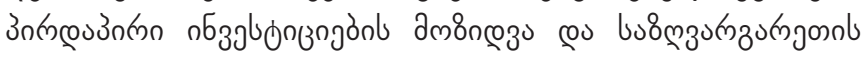

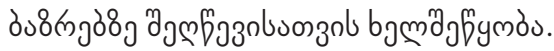

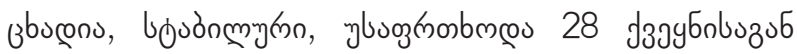

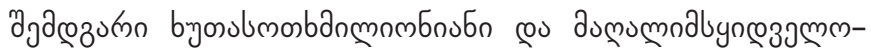

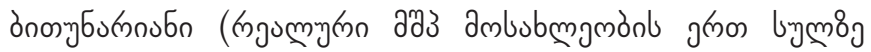

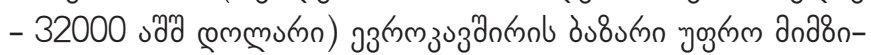

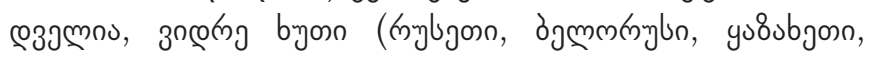

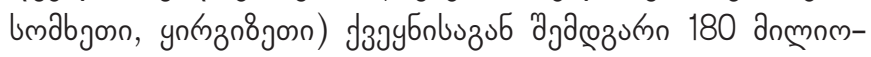

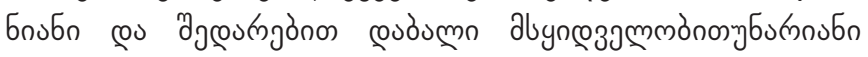

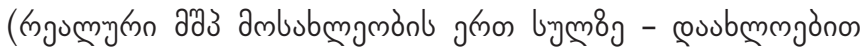

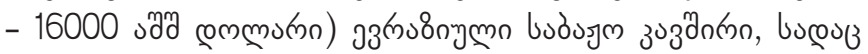

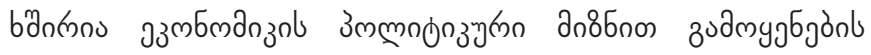
oुगdojòn.

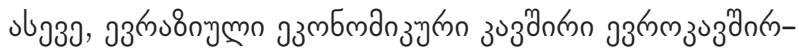

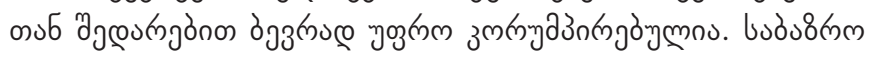

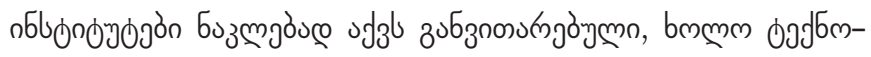

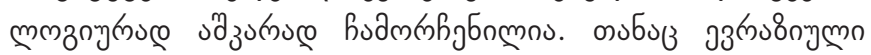

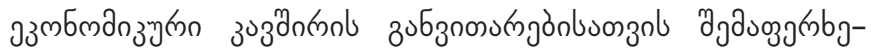

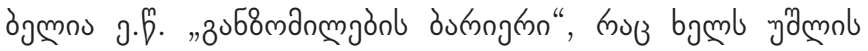

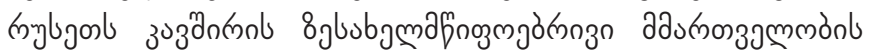

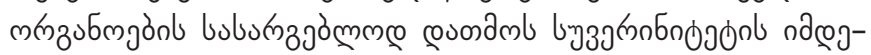

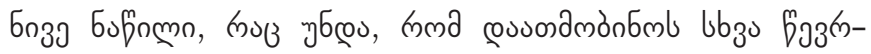

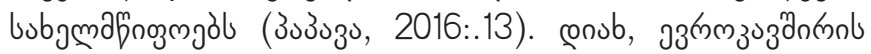

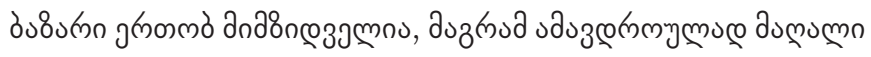

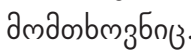

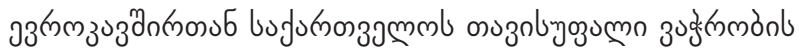

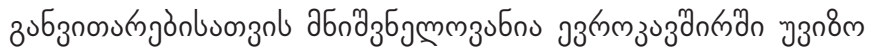




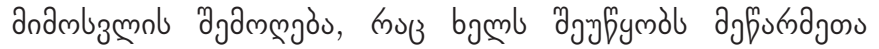

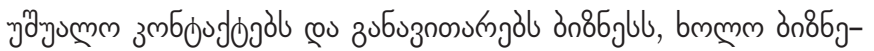

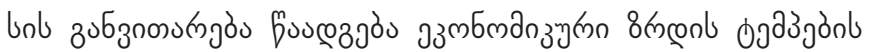

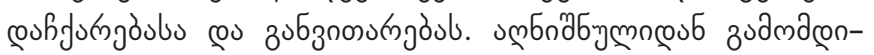

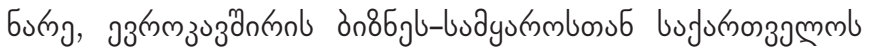

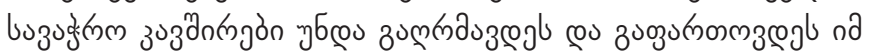

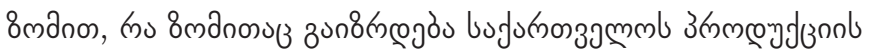

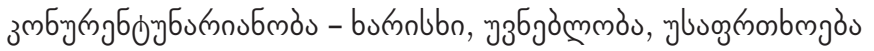

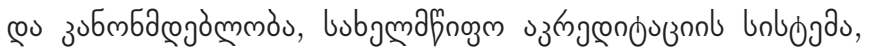

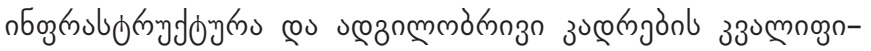

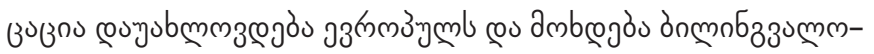

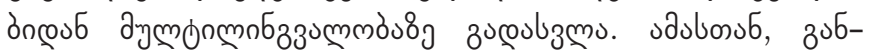

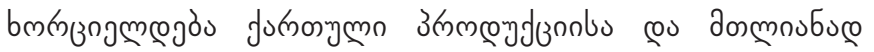

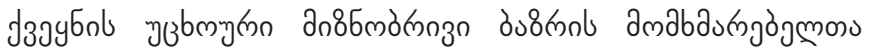

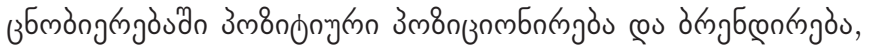

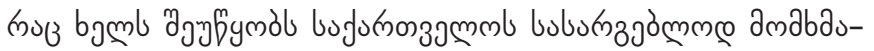

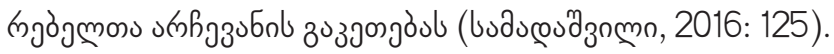

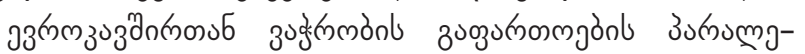

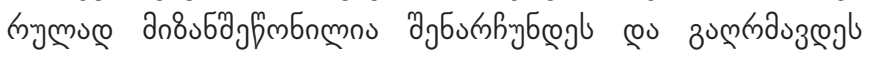

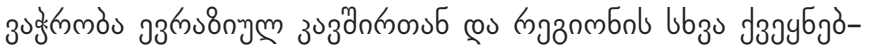

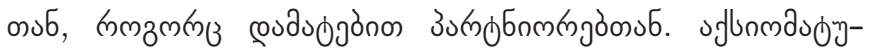

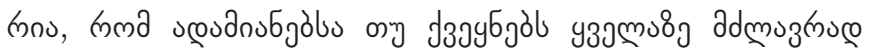

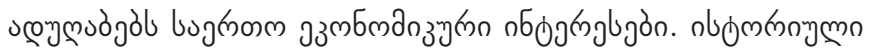

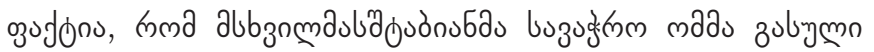

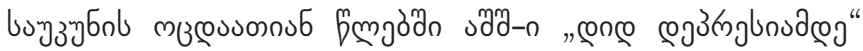

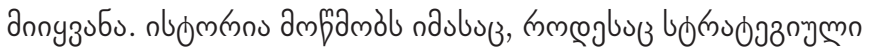

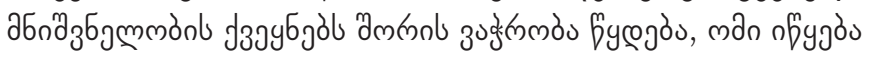
(Кабат ро lb3.2016: 13).

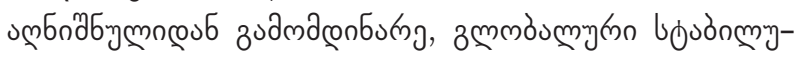

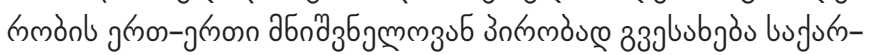

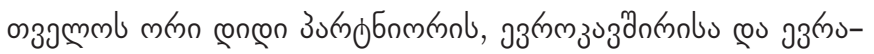

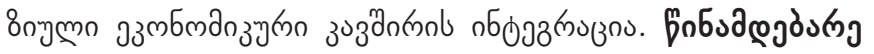

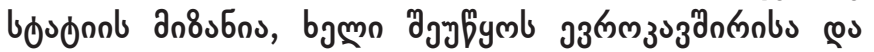

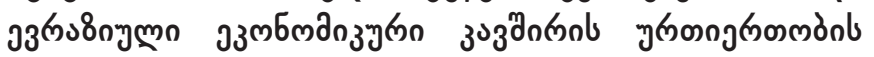
Бмкалмп8

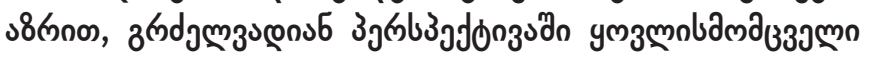

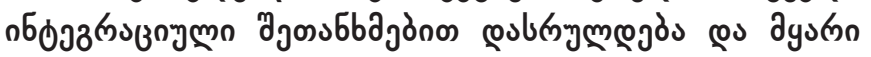

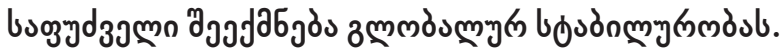

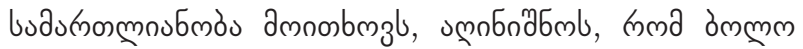

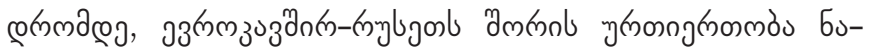

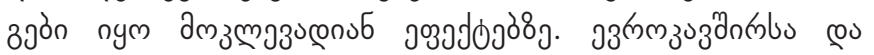

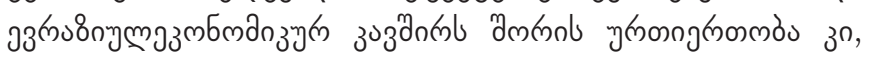

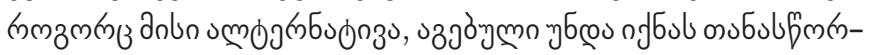

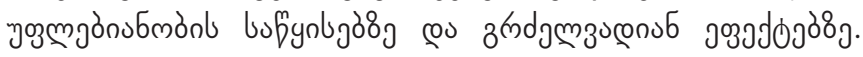

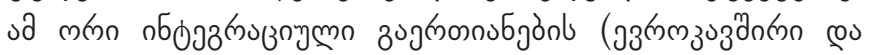

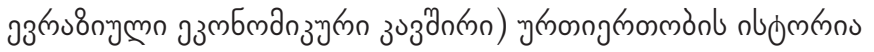

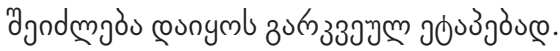

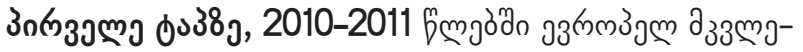

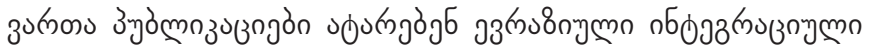

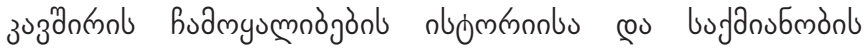

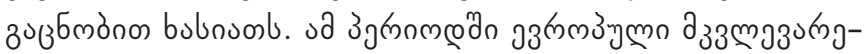

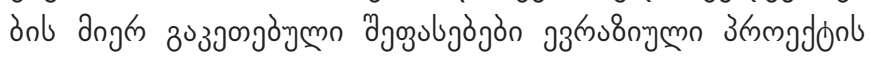

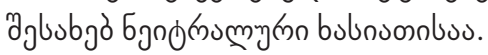

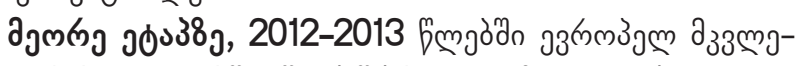

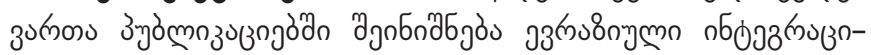

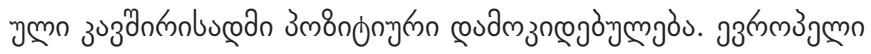

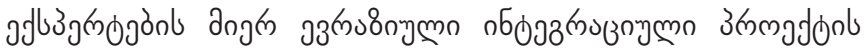

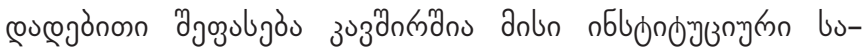

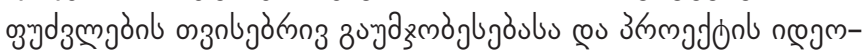

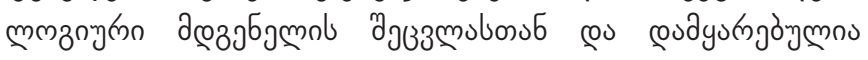

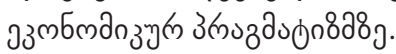

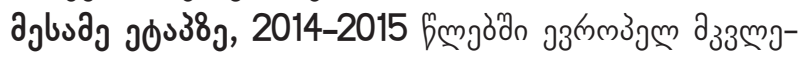

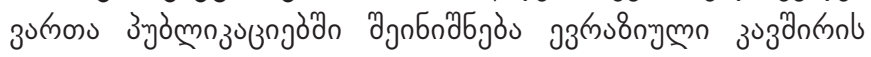

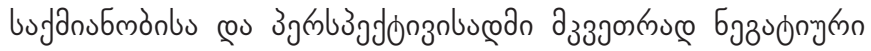

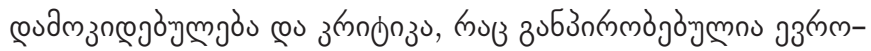

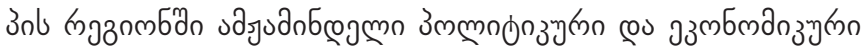

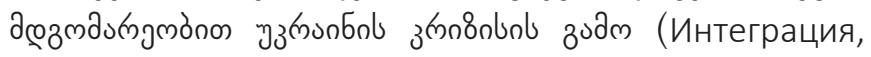
2015:3).

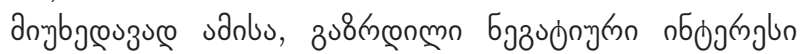

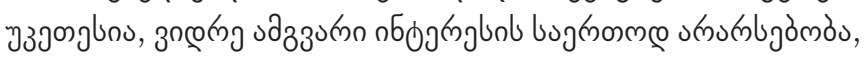

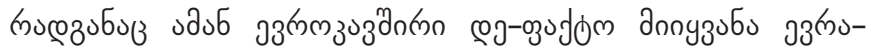

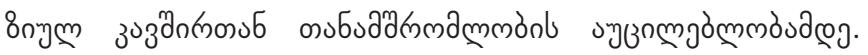

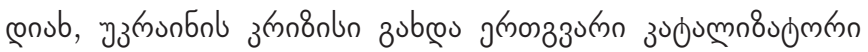

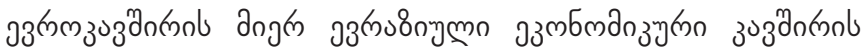

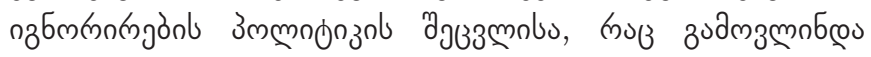

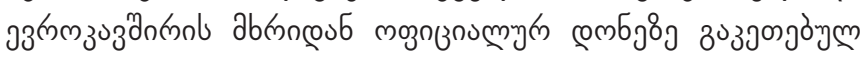

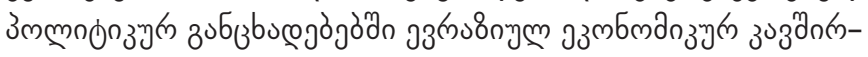

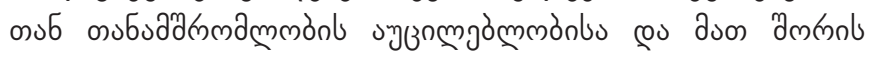

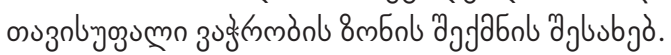

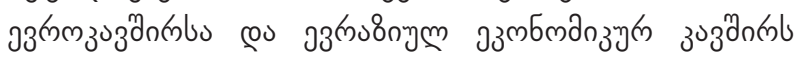

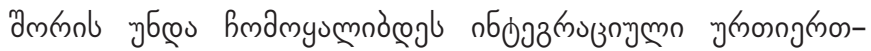

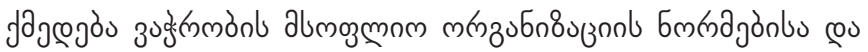

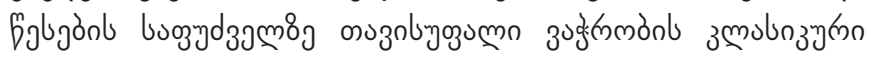

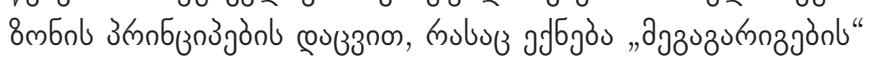
bolonomo.

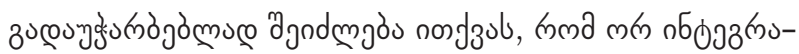

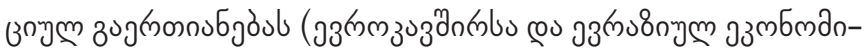

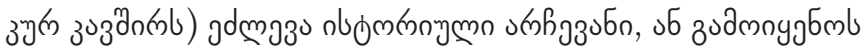

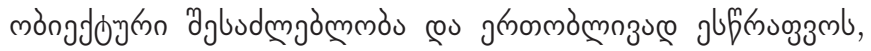

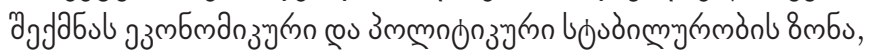

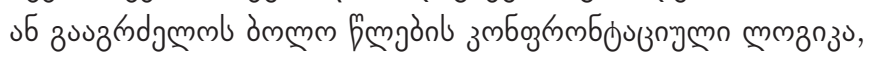

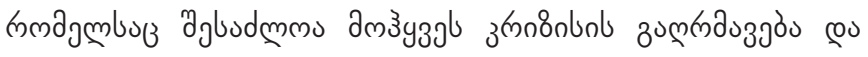

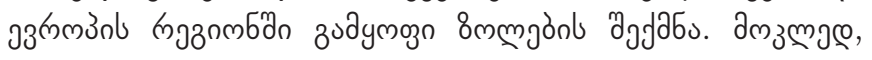

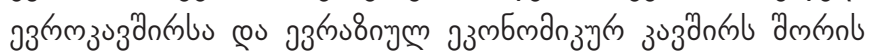

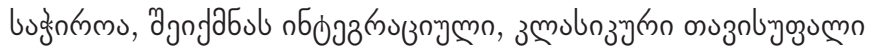

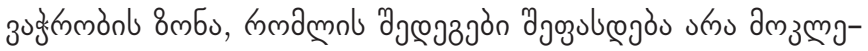

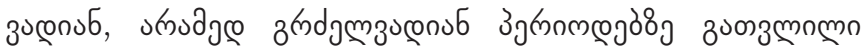
jogjdojònon. 


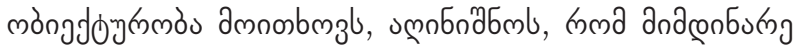

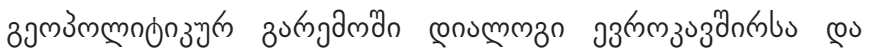

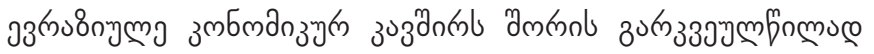

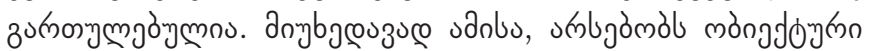

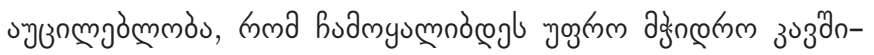

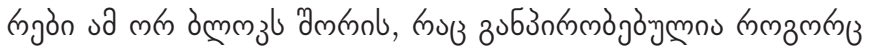

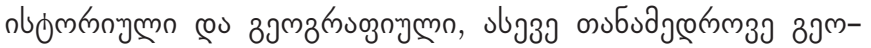

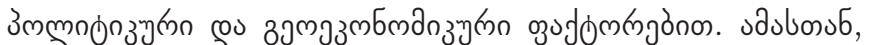

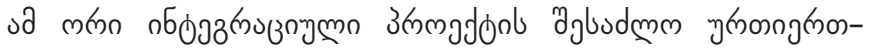

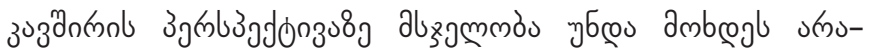

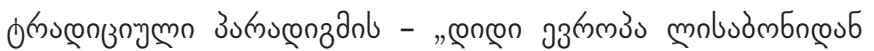

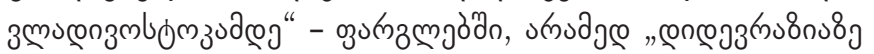

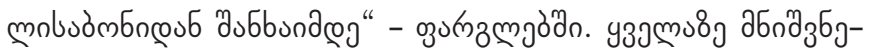

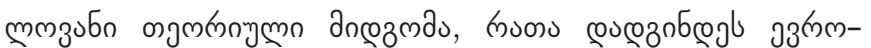
उ०3

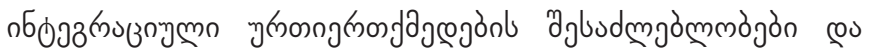

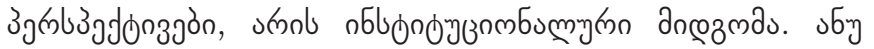

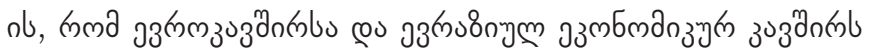

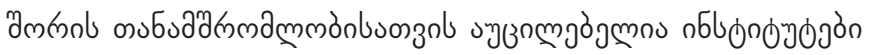

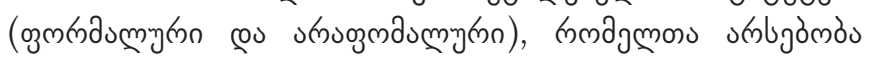

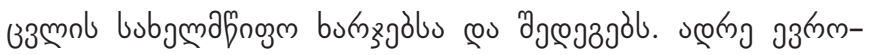

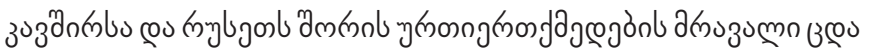

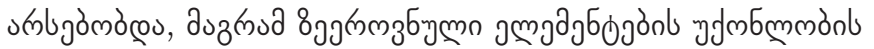

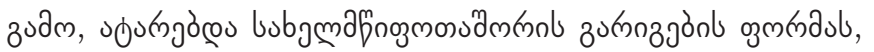

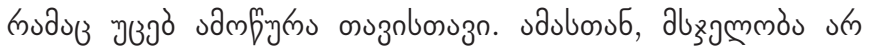
jbjou grnon

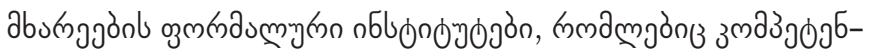

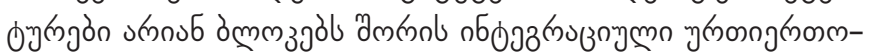

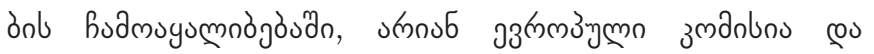

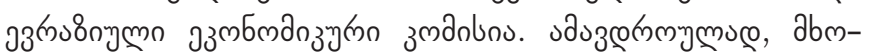

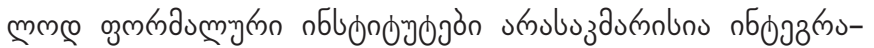

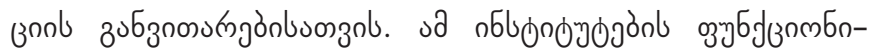

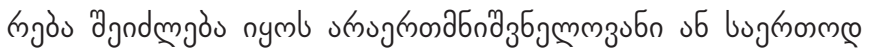

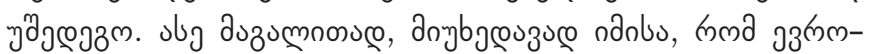

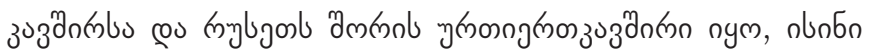

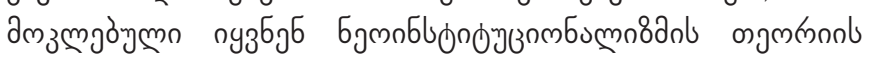

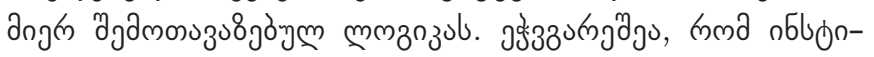

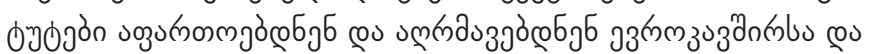

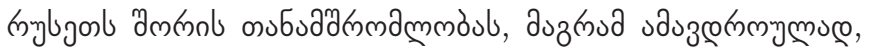

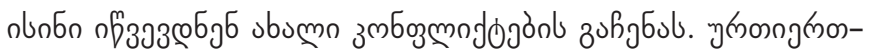

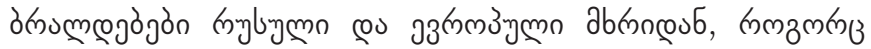

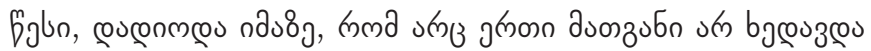

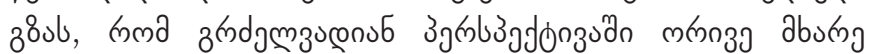

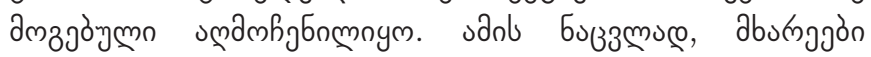

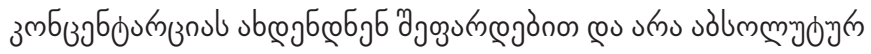

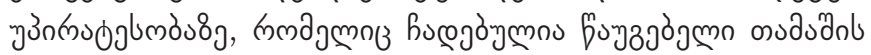

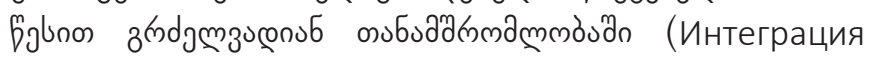
Европейского союза и Евразийского экономического

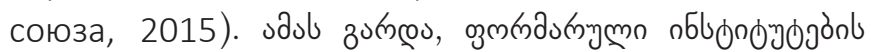

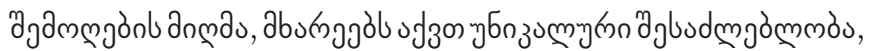

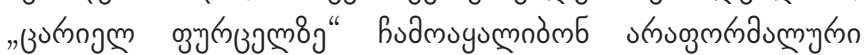

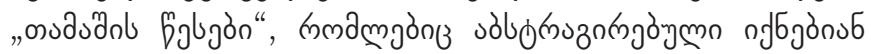

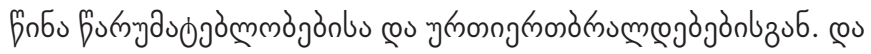

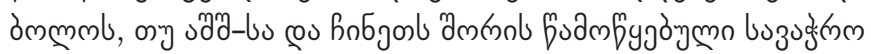

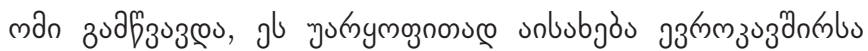

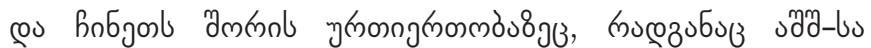

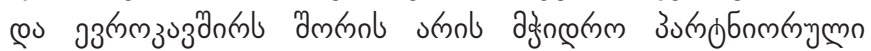

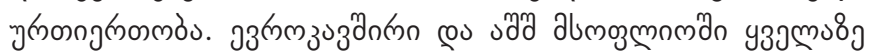

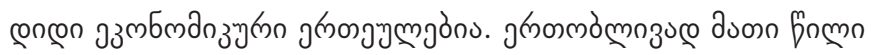

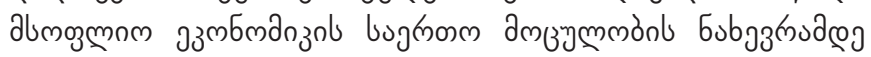

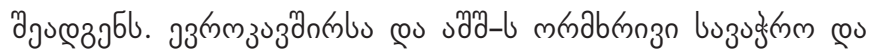

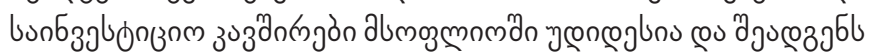

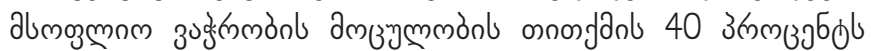

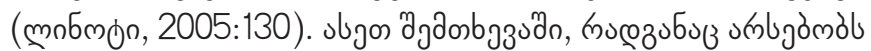

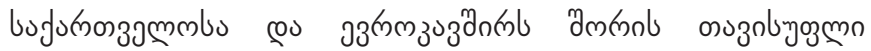

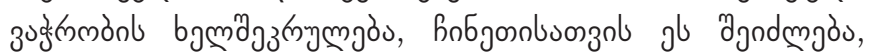

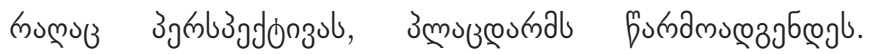

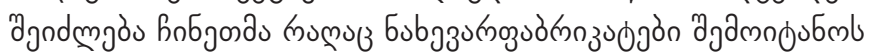

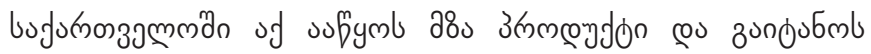

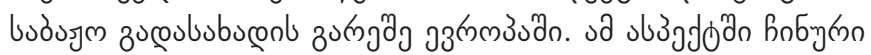
пбзjlon

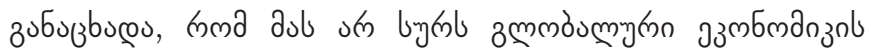

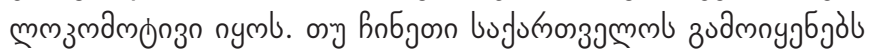

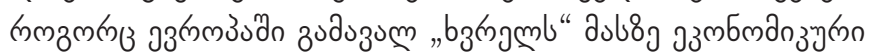

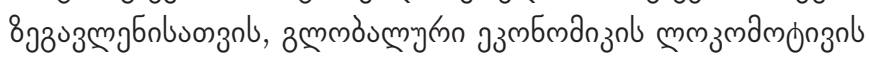

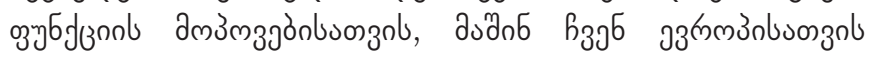

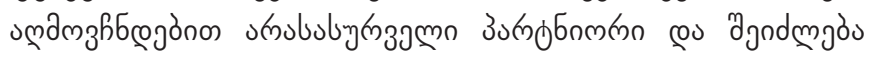

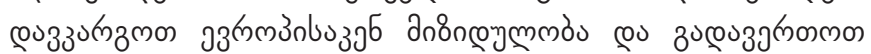

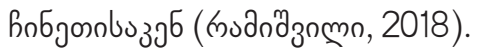

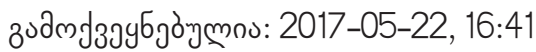




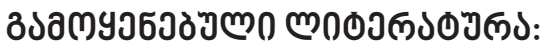

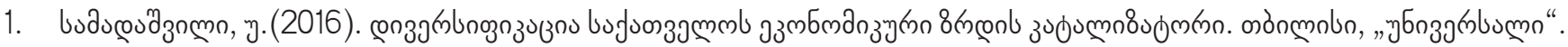

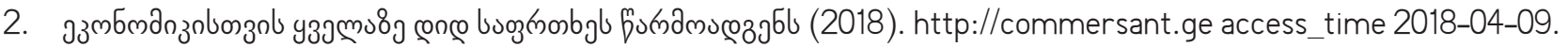

3. Интеграция Европейского союза и Евразийского экономического союза (2015). (https://knowledge.allbest. ru/international/3c0a65635a2ac69a5d53b89421216d36_2.html)

4. КабатП., ВинокуровЕ., РовенскаяЕ., ЭмерсонМ., БалашП., ХавликП., СтепановаА., КофнерЮ. К., Перебоев В. (2016) ЕВРОПЕЙСКИЙ СОЮЗ И ЕВРАЗИЙСКИЙ ЭКОНОМИЧЕСКИЙ СОЮЗ: ДОЛГОСРОЧНЫЙ ДИАЛОГ И ПЕРСПЕКТИВЫ СОГЛАШЕНИЯ. ДОКЛаД№38.

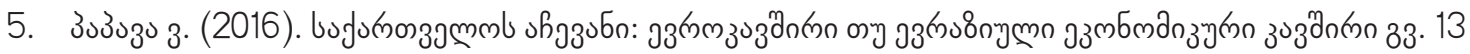

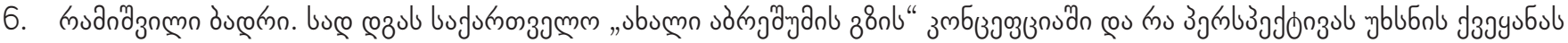
gl 3mmgdon? HTTP://OLD.1TV.GE/GE/VIDEOS/VIEW/184522.HTML.

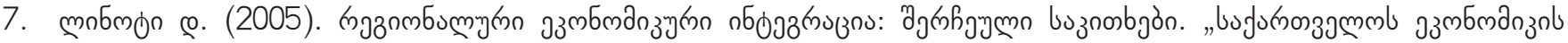

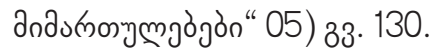




\section{INTEGRATION OF THE EU AND EURASIAN ECONOMIC UNION - THE CONDITION OF GLOBAL STABILITY}

USHANGI SAMADASHVILI

https://doi.org/10.35945/gb.2018.06.029

Doctor of Economic Sciences, Associate Professor

Ivane Javakhishvili Tbilisi State University, Georgia

u.samadashvili@mail.ru

KEYWORDS: INTEGRATIVE ASSOCIATIONS, EUROPEAN UNION, EURASIAN ECONOMIC UNION, STAGES OF INTE GRATION INTEGRATION HISTORY, SHORT-TERM AND LONG-TERM EFFECTS

\section{SUMMARY}

The historical fact is that a large-scale trade war led the United States to a "great depression" in the thirties of the last century. History also shows that when the trade between strategic countries is resolved, war begins. Given this, one of the most important conditions for global stability is the integration of the EU and the Eurasian Economic Union. Until recently, relations between the EU and Russia were short-lived.
The relationship between the EU and the Eurasian Economic Union as an alternative should be based on equality and long-term consequences. The aim of the article is to contribute to the normalization and further development of the EU and the Eurasian Economic Union, which, in our view, will eventually complete a comprehensive integration agreement and will have a solid foundation for global stability. 